\title{
Peripartum Haemorrhage: Haemostatic Aspects of the New German PPH Guideline
}

\author{
Heiko Lier ${ }^{a}$ Christian von Heymann ${ }^{b}$ Wolfgang Korte ${ }^{c}$ Dietmar Schlembach $^{d}$ \\ for the German PPH Guideline Group \\ ${ }^{a}$ Department of Anaesthesiology and Intensive Care Medicine, University Hospital Cologne, Cologne, Germany; \\ ${ }^{b}$ Department of Anaesthesiology, Intensive Care Medicine, Emergency Medicine and Pain Therapy, \\ Vivantes Klinikum im Friedrichshain, Berlin, Germany; \\ ${ }^{\mathrm{C}}$ Centre for Laboratory Medicine and Haemostasis and Haemophilia Centre, St. Gallen, Switzerland; \\ ${ }^{d}$ Department of Obstetrics and Gynaecology, Vivantes Klinikum Neukölln, Berlin, Germany
}

\section{Keywords}

Peripartum haemorrhage $\cdot$ Standard operating procedures - Uterotonics · Haemostasis .

Tranexamic acid - Coagulation factor concentrates . Blood conservation

\section{Summary}

Peripartum haemorrhage remains one of the main causes of maternal mortality world-wide. The German, Austrian and Swiss Societies of Gynaecology and Obstetrics have updated the current guidelines for the treatment of peripartum haemorrhage together with the German Society of Anaesthesiology and Intensive Care Medicine and the Society of Thrombosis and Haemostasis Research. The recommendations have been the result of a thorough review of the available scientific literature and a consensus process involving all members of the guideline group. A key element of the anaesthesiological and haemostatic management is the development of a multidisciplinary standard operating procedure combining surgical as well as medical and haemostatic treatments depending on the severity of bleeding. The guideline underscores the value of clinical and laboratory diagnostics of peripartum haemorrhage as early as possible, even pre-emptively. This allows for an early identification of causes of bleeding and a specific treatment. The guideline comprises evidence-based recommendations for the use of uterotonics, tranexamic acid and blood products such as factor concentrates, fresh frozen plasma, platelet concentrates, packed red blood cells, recombinant activated factor VII and desmopressin. In addition, recommendations for blood conservation strategies involving the use of cell salvage, permissive hypotension and transfusion triggers are given.

(c) 2017 S. Karger GmbH, Freiburg

\section{Introduction}

Peripartum haemorrhage (PPH) accounts for about one-quarter to one-third of all maternal deaths. World-wide, 7 women die of PPH every hour [1]. Developing regions account for the fast majority of maternal deaths [2]. But there is also strong evidence that the rate of PPH is actually increasing in industrial counties: while a mother's risk for life-threatening bleeding was expected to be $1 / 1,000$ at the end of the last century [3], it is found to be $1.2 \%$ (England, 2008) [4] to 11.4\% (USA, 2006-2010) [5] today. The main reason for this increase is the growing frequency of uterine atony [6]. An increasing frequency of labour induction or support with oxytocin as well as a rapid increase in caesarean deliveries within the past decade seem to be the main causes [7]. Obstetrics accounted for $30 \%$ of all anaesthesia-related haemorrhage claims in the US, and anaesthesia care for PPH was often judged inappropriate $[8,9]$.

In 2013, the informal D-A-Ch-algorithm was published by an interdisciplinary group of experts from Germany (D), Austria (A), and Switzerland (Ch) [10]. For Germany, the Association of the Scientific Medical Societies (Arbeitsgemeinschaft der Wissenschaftlichen Medizinischen Fachgesellschaften; AWMF) advises

\section{KARGER}

(c) 2017 S. Karger GmbH, Freiburg

Fax +497614520714 
Table 1. The AWMF's classification of the strength of consensus

\begin{tabular}{ll}
\hline Strong consensus & agreement of $>95 \%$ of the participants \\
Consensus & agreement of $>75-95 \%$ of the participants \\
Majority agreement & agreement of $>50-75 \%$ of the participants \\
No consensus & agreement of $<50 \%$ of the participants \\
\hline
\end{tabular}

on matters and tasks of fundamental and interdisciplinary interest in medicine, develops evidence-based recommendations and resolutions and disseminates them at the institutions occupied with such tasks, i.e., in research strategies, education and postgraduate training. As the AWMF's 2008 guideline $015-063$ on prevention and treatment of $\mathrm{PPH}$ was to be updated, a representative committee of 13 official delegates of the Austrian, Swiss' and German Societies of Gynaecology and Obstetrics, the German Midwifes' Society, the Society of Thrombosis and Haemostasis Research, and the German Society of Anaesthesiology and Intensive Care Medicine was formed and published the new guideline in April 2016.

A systematic PubMed search with the query 'postpartum haemorrhage, RCT, humans, 2008-06/2015' found 142 hits. 74 of them were on uterotonics, 29 on the management of labour, 9 on tranexamic acid (TxA) (7 on prophylactic use, 1 on therapeutic use, 1 in the setting of the WOMAN trial), 2 on transfusion use (both from the WOMB trial), 2 on the use of fibrinogen (both from the Fib-PPH trial) and 26 others. Although these articles were the basis of our guideline, in general, the publications were not comparable to each other as they differ relevantly in their definitions, various application details as well as other essential issues. Therefore, and despite the fact that one of the first articles on this topic was published as early as 1901 [11], strong evidence-based recommendations are currently impossible for almost all steps of PPH management. This is one of the key problems in $\mathrm{PPH}$ treatment and causes publications of different recommendations by different international societies [12]. The choice of treatment options and drugs for PPH might also be quite different depending on the local and regional setting. Thus, the aim of the working group was to create a structured, consensus-based guideline for the Germanspeaking countries and to formulate recommendations according to the AWMF's classification of the strength of consensus [13] (table 1). The purpose of this article is to describe the most important recommendations for haemostatic management of $\mathrm{PPH}$; these will be marked in italic letters followed by the consensus in curly brackets.

Specific obstetrical actions like sonographic risk stratification, compression sutures, vessel ligatures, arterial catheter embolisation, and others are essential parts for effective management of PPH and are listed and discussed in the guideline but are beyond the scope of this article. Additionally, while uterotonics are of great importance and first-line options for atonic bleeding and, therefore, an essential and large part of the guideline, this haemostaseological article will only give a short view on them.
Table 2. Risk factors for $\mathrm{PPH}$

\begin{tabular}{ll}
\hline Tone & $\begin{array}{l}\text { uterine distension (multiple gestation, polyhydramnion, } \\
\text { foetal macrosomia) }\end{array}$ \\
& $\begin{array}{l}\text { uterotonics } \\
\text { quick or prolonged labour } \\
\text { (long) oxytocin exposure } \\
\text { chorioamnionitis } \\
\text { uterus myomatosus }\end{array}$ \\
\hline Tissue & $\begin{array}{l}\text { retained placenta } \\
\text { abnormal placental implantation (placenta adhaerens, } \\
\text { accreta / increta / percreta) }\end{array}$ \\
\hline Trauma & $\begin{array}{l}\text { vulvovaginal injury } \\
\text { episiotomy / perineal suture } \\
\text { uterine rupture } \\
\text { inversion of the uterus }\end{array}$ \\
\hline Thrombin & $\begin{array}{l}\text { gestational: thrombocytopenia with HELLP syndrome, } \\
\text { placental abruption, amniotic fluid embolism) } \\
\text { other: VWD, plasmatic coagulopathies, platelet function } \\
\text { disorders, factor deficiencies (loss, consumption, dilution) }\end{array}$ \\
\hline
\end{tabular}

\section{Definition, Risk Factors and Preparation}

Still, there is no common international definition of $\mathrm{PPH}$. The World Health Organisation (WHO) defines PPH as a blood loss of $500 \mathrm{ml}$ or more within $24 \mathrm{~h}$ of birth, independently of the mode of delivery [14]. The new German guideline maintains the differentiation between blood loss $\geq 500 \mathrm{ml}$ following vaginal and $\geq 1,000 \mathrm{ml}$ following caesarean delivery [15] \{strong consensus of the committee\}. PPH can be divided into primary (i.e., within $24 \mathrm{~h}$ after delivery; $>80 \%$ caused by atony) and secondary ( $24 \mathrm{~h}$ to 12 weeks after delivery) PPH [15]. Most peripartum bleedings happen within the first $4 \mathrm{~h}$ after delivery. A thorough patient history is recommended; standardised questions should search for nose and dental bleeding, haematoma (without adequate trauma), use of specific drugs (nonsteroidal antiphlogistics, platelet inhibitors), and especially menorrhagia or prior bleedings during surgery/birth [16]. The risk factors for PPH can be memorised using the 4 T's: tone, tissue, trauma, and thrombin (table 2). Of note, a large proportion of women developing PPH do not have identifiable risk factors, suggesting that essentially every woman might be at risk [17]. While only about one-third of pregnancies have risk factors, those women will be responsible for almost two-thirds of massive transfusions [18]. The first step of PPH management is to recognize that PPH is not a diagnosis, but a clinical sign of an underlying condition that, by itself, requires diagnosis $[19,20]$.

It is essential for every hospital with an obstetric department to develop a standard operating procedure (SOP) including a massive transfusion protocol for PPH management, adapted to this hospital's infrastructure and logistics. This SOP should aim at an early identification of a bleeding parturient and a combined surgical, interventional, and haemostatic management to stop the bleeding [21] \{strong consensus of the committee\}. 
An audit and evaluation of the hospital's logistics is recommended even without risk factors and is the basis of adequate therapy. The following procedures should be implied for women at risk \{strong consensus of the committee\}:

- adequate venous access for every woman in labour [22], at least one large bore venous access in case of bleeding

- administering uterotonics (oxytocin, prostaglandins)

- 'emergency laboratory measurements' (complete blood count, blood gas analysis, prothrombin time (PT), activated partial thromboplastin time (aPTT), fibrinogen, antithrombin, if possible thrombelastography (TEG ${ }^{\mathrm{TM}}$ (Haemonetics, Braintree, MA, USA)) or rotational thromboelastometry (ROTEM ${ }^{\mathrm{TM}}$ (Tem International, Munich, Germany)))

- obstetrician and anaesthesiologist on site, experienced obstetrician, and experienced anaesthesiologist on call

- cross-matching (or, where appropriate, type \& screen), ordering of red blood cells (RBCs), fresh frozen plasma (FFP), and platelets

- haemostatic agents (TXA, fibrinogen, factor XIII, recombinant activated factor VII ( $r F V I I a)$ ).

Concerning laboratory parameters, one should keep in mind that due to physiological alterations, pregnancy has its own reference values for almost every analysis, especially in haemostasis. Due to increasing factor concentrations with developing pregnancy, patients with von Willebrand disease (type I) or haemophilia (only A, as factor IX does not increase) do not have an elevated bleeding risk during pregnancy compared to healthy ones. Nevertheless, this risk is greatly augmented in the postpartum period $[17,23,24]$.

Recording blood loss during and after birth is a cornerstone of postpartum care [2]. We recommend collecting blood-soaked tissue, bandages, linens and clots to quantify the amount of blood loss \{consensus of the committee\}. Yet, the time frame and dynamics of bleeding are of great importance [16].

\section{Uterotonics}

Physiologically, myometrial contractions are the main determinant of placental separation and haemostasis ('physiological sutures' or 'living ligatures' [25]). Prophylactic use of uterotonics is standard of care world-wide. Alongside general interventions such as stabilisation of the patient's haemodynamics, causal therapy of PPH consists of medical and/or surgical treatments that must be performed quickly, coordinated and often simultaneously \{strong consensus of the committee\}.

Oxytocin is generally regarded as the first-line uterotonic in the prevention and management of PPH caused by uterine atony. The minimal effective dose of oxytocin (ED90) is 0.35 IU [26] or 0.29 $\mathrm{IU} / \mathrm{min}[27,28]$. Of note, women with prior exposure to exogenous oxytocin for induction/augmentation of labour may require a higher initial rate (receptor desensitisation and down-regulation) [7, 29-31].

The guideline recommends the following procedure: 3-5 IU (i.e., one vial) oxytocin in $10 \mathrm{ml}$ saline to be given slowly as a single intra- venous bolus (preferably as short infusion); if necessary, this can be followed by 10-40 IU of oxytocin in 500-1,000 ml saline as a continuous infusion (dose-depending on the clinical situation, particularly uterine contractions) $[15,32]$ \{strong consensus of the committee\}.

The dose range of 3-5 IU refers to the different content in one vial of oxytocin in Germany, Swiss and Austria but is also recommended by other authors $[31,33]$. More than half of the patients receiving oxytocin as a bolus suffer a reduction of systolic blood pressure (approximately $25 \mathrm{~mm} \mathrm{Hg}$ for $2.5 \mathrm{~min}$ ) [7]. Intravenous oxytocin as an infusion, instead of a bolus, causes less cardiovascular instability; however, the coronary circulation may respond with vasoconstriction, diminished blood flow or both [29]. Although these physiological changes may be tolerated by a healthy parturient, those with hypovolaemia or co-morbid conditions may not be able to compensate, and close cardiovascular monitoring is therefore recommended [29].

Carbetocin is a synthetic, long-acting agonist to oxytocin, with a half-life approximately 4-10 times longer than oxytocin. It is currently licensed for prevention of uterine atony after delivery by caesarean section in spinal or epidural anaesthesia only [9]. In individual cases, the use of carbetocin to treat PPH has been reported [34].

Methylergometrine, an ergot alkaloid, causes intense and sustained contractions of the myometrium [1]. Due to possibly lifethreatening side-effects and the fact that better alternatives are available, methylergometrine should only be applied with utmost caution \{strong consensus of the committee\} and not as an intravenous bolus, but, if needed, by continuous infusion \{consensus of the committee\}.

Prostaglandins increase oxytocin-induced myometrial contractions by stimulating the expression of oxytocin receptors [35]. Sulprostone, an injectable, synthetic prostaglandin E2 analogue, is generally regarded as second-line medication if oxytocin/carbetocin are not effective [9]. Side-effects include bronchoconstriction, pulmonary hypertension, myocardial ischaemia and cardiac arrest $[35,36]$. If first-line uterotonics are not available or effective, sulprostone should be used immediately. Continuous haemodynamic monitoring is recommended \{consensus of the committee\}. A simultaneous administration of oxytocin receptor agonists and prostaglandins should not be performed due to the increased risk of lifethreatening cardiovascular side-effects strong consensus of the committee\}.

\section{Hysterectomy}

Emergency hysterectomy should be considered if blood loss exceeds approximately 2-31 and is refractory to surgical and haemostatic measures. However, all efforts described in this article (and essential surgical interventions like compression sutures or vessel ligatures) are intended to prevent this situation [37]. Further indications for emergency hysterectomy are a septic uterus, in which hysterectomy is the causative measure to save the mother's life. 

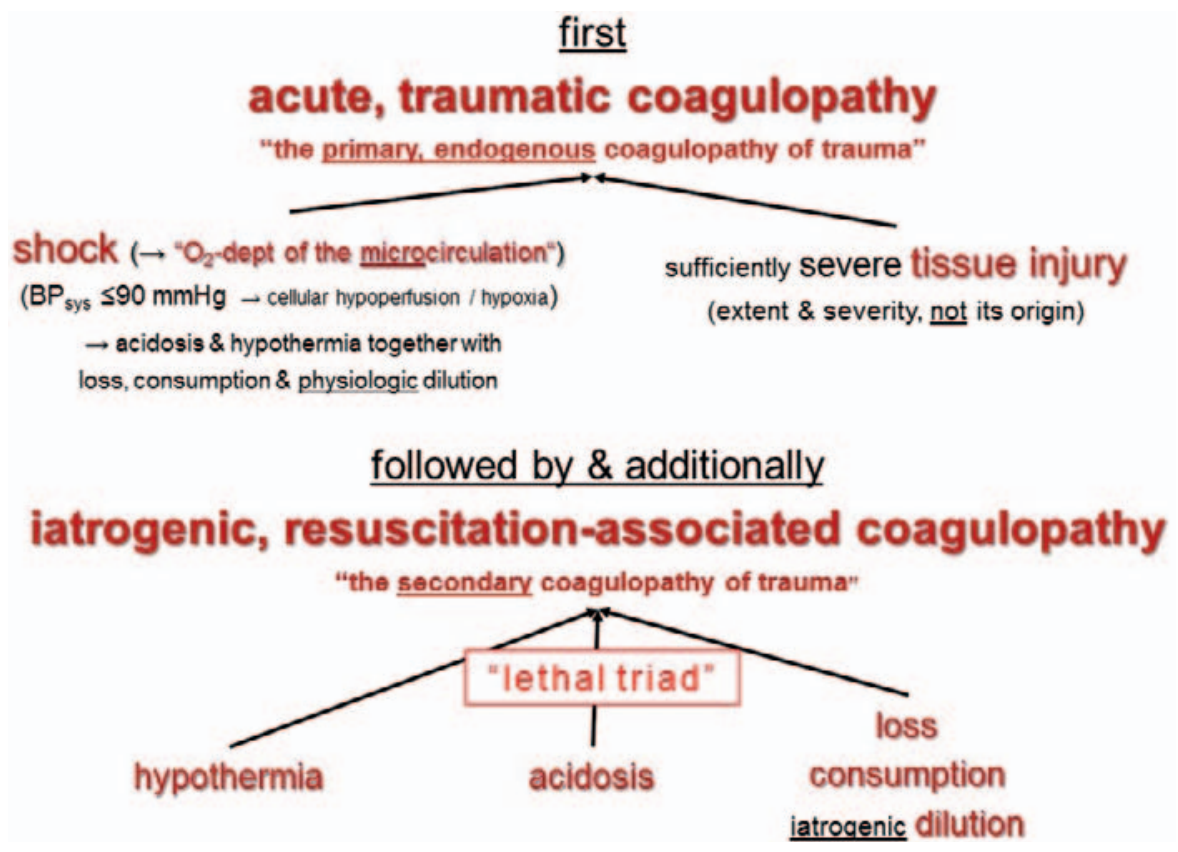

Fig. 1. Bleeding by trauma-induced coagulopathy (modified after [88]).

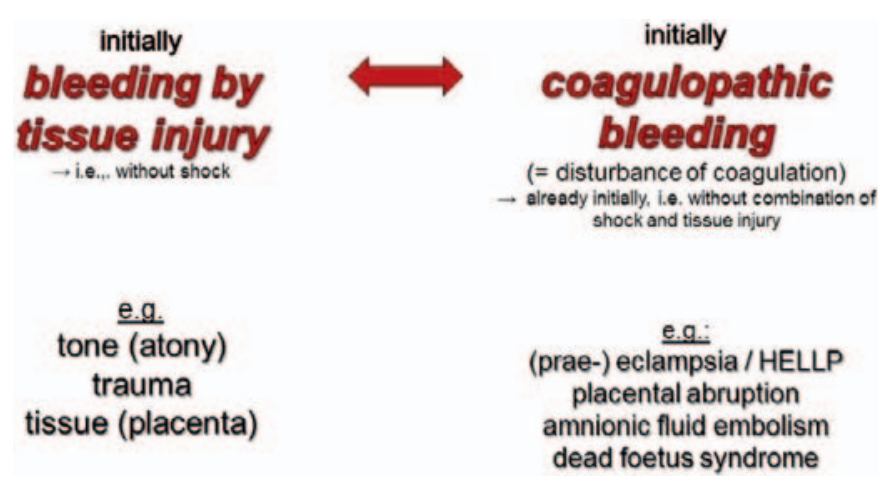

Conservative treatment to preserve the uterus is only reasonable if the patient does not bleed life-threateningly and has relatively stable haemodynamics. Therefore, a hysterectomy should not be indicated too late $[28,38]$ \{strong consensus of the committee\}. Every emergency hysterectomy carries a high risk for massive transfusion [39]; the team needs to be prepared. To avoid unnecessary blood loss, a compression of the aorta [40] or a Hamilton manoeuvre is possible. If hysterectomy does not stop the bleeding, a packing of the pelvis and abdomen with damped swabs may be performed \{consensus of the committee\}.

\section{Haemostasis and Coagulation Management}

At term, a woman's physiology is altered, which is especially true for haemostasis. Nevertheless, many authors recommend the adoption of diagnostic and therapeutic findings from multiple trauma to PPH [41-43]. Cellular hypoperfusion and shock, the key-players of traumatic coagulopathy, may also trigger obstetric hyperfibrinolysis: The vascular bed of the placenta has an endothelial cell-like nature, expresses tissue factor and thrombomodulin, and releases plasminogen activator inhibitor-2 (PAI-2) [44]. Additionally, pregnant women do have an increased rate of glycocalyx shedding with increased levels of syndecan-1, providing an additional anticoagulant mechanism ('autoheparinisation') [45]. Specific obstetrical triggers of a coagulopathy are the wash-in of tissue factor of foetal, placental or amniotic origin, (mainly Gram-negative) infections and decomposition of uterine tissue, leading to consumption of coagulation factors, thrombocytopenia and hyperfibrinolysis in various combinations and extents [46].

Different causes of PPH will need different primary therapies. The main problem in $\mathrm{PPH}$ is to try to differentiate between surgical

bleeding caused by tissue and vascular injury and microvascular bleeding due to a concurrent impairment of coagulation (= coagulopathy). Regardless of the primary cause of $\mathrm{PPH}$, all will result in coagulopathy if early intervention is not successfully applied [47]. A disturbed coagulation is often an early pathology in $\mathrm{PPH}$, which can appear before a dilutional coagulopathy occurs [17, 48]. Thus, the team must always discriminate between bleeding with shock and severe tissue injury (fig. 1), initial bleeding by tissue injury, and initial coagulopathic bleeding (fig. 2).

Diagnostics to differentiate these causes of bleeding are to be performed in a timely manner. Treatment should start as soon as possible and not be delayed due to laboratory diagnostics. As a rule, if there are no surgical or patient-related causes to explain the bleeding, bleeding should be considered to be a PPH with acquired coagulopathy \{strong consensus of the committee\}.

In case of the triad of 'prolonged bleeding + haemorrhagic shock + coagulopathy', procedures should be as follows \{consensus of the committee\}: 
- Early surgical bleeding control by the obstetrician on duty.

- Concurrent correction of hypovolaemia, hypothermia, disturbed acid-base-balance, and coagulopathy by the anaesthesiologist. When appropriate, followed by a paused operation for further stabilisation on the intensive care unit.

- Definitive surgical care in the stabilised patient by an experienced surgeon.

During active bleeding, every iatrogenic aggravation of the bleeding tendency, e.g., by infusion of artificial colloids (increased dilution), or supranormal blood pressure should be avoided (strong consensus of the committee\}. Today, haemostatic therapy is performed with antifibrinolytics and either labile (e.g., FFP), stabile (e.g., lyophilised factor concentrates) or cellular (e.g., platelet concentrates) components that must start as early as possible to prevent an additional dilutional coagulopathy \{consensus of the committee\}.

The term 'disseminated intravascular coagulation (DIC)' refers to a specific clinical picture associated with initial intravascular thrombosis. However, most cases of PPH associated with a localised consumption of coagulation factors do not show the classical picture of a systemic DIC [38]; exceptions can be seen with pre-eclampsia, amniotic fluid embolism and dead foetus syndrome [49]. After delivery, the already augmented fibrinolysis with ongoing breakdown of cross-linked fibrin may severely impair the haemostatic outcome [38]. In any case, a potentially increased fibrinolytic activity should be stopped by administration of TxA before substitution of fibrinogen is considered [21] \{strong consensus of the committee\}. The working group of Ducloy-Bouthors [50] showed that the therapeutic application of TxA in bleeding PPH patients caused a significant reduction of blood loss, of patients with a haemoglobin decrease $>4 \mathrm{~g} / \mathrm{dl}$, a reduction of the number of transfused RBCs and a shorter bleeding duration. Analysing these study's haemostasis parameter provided biological evidence of an early increase in D-dimers and plasmin-antiplasmin complexes associated with active $\mathrm{PPH}$ and its attenuation by the early use of TxA [51]. The publication of the WOMAN (World Maternal Antifibrinolytic) trial will hopefully add further knowledge concerning the combination of TxA and PPH [52]. Early use of fibrinogen in obstetric bleedings due to a 'defibrination syndrome' was published as early as 1959 [53]. Studies with more than 1,700 women showed that a fibrinogen concentration $<3 \mathrm{~g} / \mathrm{l}$ and especially $<2 \mathrm{~g} / \mathrm{l}$ in early $\mathrm{PPH}$ will result in a progression, whereas a fibrinogen concentration $>4 \mathrm{~g} / \mathrm{l}$ will not [54]. Even after vaginal delivery, for each $1 \mathrm{~g} / \mathrm{l}$ increase of pre-delivery fibrinogen level, the risk of a bleeding $\geq 1,000 \mathrm{ml}$ decreases by a factor of 0.405 (95\% CI 0.219-0.750; $\mathrm{p}=$ 0.004) [55]. In women with PPH or a history of it, fibrinogen concentration should be determined, as a fibrinogen concentration < $2 \mathrm{~g} / \mathrm{l}$ may identify those at increased risk for severe bleeding \{consensus of the committee\}. A target level for fibrinogen substitution in a bleeding parturient might be $>2 \mathrm{~g} / \mathrm{l}(200 \mathrm{~g} / \mathrm{dl})$ [49]. A prospective cohort study proved an algorithm for ROTEM-guided fibrinogen concentrate administration to be superior to use of 'shock packages' [56]. After finalisation of the guideline, the Fib-PPH-trial (Fibrinogen Concentrate as Initial Treatment for Postpartum Haemorrhage) was published [57] that described no evidence for the pre- emptive use of a fixed dose of $2 \mathrm{~g}$ of fibrinogen concentrate in severe $\mathrm{PPH}$. However, the mean fibrinogen level was $4.5 \mathrm{~g} / \mathrm{l}$ before intervention questioning the rationale of fibrinogen supplementation. Furthermore, only a minority of patients was treated with TxA, and $15 \%$ of the patients screened for the trial could not give informed consent as their bleeding was too severe.

There are some observations with positive outcome [58], but little evidence concerning the use of desmopressin (DDAVP) in PPH. The European Society of Anaesthesiology recommended DDAVP for disturbed platelet function caused by certain drugs, hypothermia or acidaemia [21].

Despite controversial evidence and lack of prospective randomised controlled trials (RCT) and before an emergency hysterectomy, an individual treatment decision with rFVIIa might be made with a dose of $90 \mu \mathrm{g} / \mathrm{kg} \mathrm{BW}[59,60]$ if the patient has been adequately treated with all other mentioned therapeutic options, these other options were not sufficiently effective and the patient's family planning is not complete [17]. Due to an increased risk of (arterial) thromboembolism [61], rFVIIa should only be an ultima ratio therapy. Additionally, coagulation factors and platelet count should be optimised [21] \{consensus of the committee\}. After finalisation of the guideline, a French RCT showed that rFVIIa reduces the need for specific second-line therapies in about 1 of 3 patients [62]. Albeit, only the number of arterial embolisation was significantly lower in the intervention arm. Due to various issues (large differences of median haemoglobin and fibrinogen levels in the groups; contrary to protocol, no measurement of blood loss; no differences in required blood products; venous thromboembolisms in 5\% of rFVIIa patients; ...), these results are to be interpreted with caution, especially the 'compassionate' rFVIIa use in $19 \%$ of the patients in the standard care group.

Summarising, current data on haemostatic treatment options recommend \{strong consensus of the committee\}:

- an escalating (i.e., step-by-step approach) concept to be adapted to each hospital's infrastructure and logistics [21],

- an early, preferably immediate application of TxA [50, 63],

- a stabilisation of the physiological preconditions of haemostasis $\left(\mathrm{pH}\right.$, temperature, ionised calcium $\left.\left(\mathrm{Ca}^{2+}\right)\right)[64]$, at least in $p a-$ tients with continued bleeding, diagnosing the bleeding's cause by viscoelastic tests or conventional laboratory data [21, 49],

- the earliest substitution possible of coagulation factors with factor concentrates and/or FFP for active bleeding due by coagulopathy caused by loss or dilution of coagulation factors,

- optimising the platelets' number (100,000 / $\mu$ l for transfusion-requiring bleeding).

In fact, the coagulopathy of $\mathrm{PPH}$ entails a third, late, and prothrombotic state. In addition to the pro-thrombotic state of pregnancy itself, massive transfusion and $\mathrm{PPH}$ are recognised to be risk factors for the development of postpartum venous thromboembolism $[17,38,65]$. Within 24 h of reliably stopping the haemorrhage, a pharmacological thrombosis prophylaxis is required [17] \{strong consensus of the committee\}. The decreased antithrombin activity after $\mathrm{PPH}$ (some women presented with an absolute activity below $0.5 \mathrm{kIU} / \mathrm{l}$ ) must be considered when administering 
coagulation factors, especially prothrombin complex concentrate [66], to parturients [67]. Substitution with antithrombin might aim at $\geq 80 \%$ [68] or $\geq 0,8 \mathrm{kIU} / \mathrm{l}$ [69]. However, antithrombin substitution is controversially discussed and not equally accepted in different countries.

\section{Further Aspects of PPH Management}

The regular British Confidential Enquiries into Maternal Deaths / MBRRACE-UK (Mothers and Babies: Reducing Risk through Audits and Confidential Enquiries across the UK) reports repeatedly state that most PPH morbidity and mortality could have been prevented and 'too little is done too late'. As stated above, estimation of blood loss is often inaccurate. Yet, the consensus conference wanted to sensitise junior physicians to PPH's severity and support them to call for senior assistance early. To the best of our knowledge, this guideline is the first to use relatively low estimated blood losses as indices for this purpose.

The timely call for qualified help is recommended in ongoing bleeding $>500 \mathrm{ml}$ and $>1,000 \mathrm{ml}$ for vaginal and caesarean delivery, respectively, and essential if blood loss is $>1,500 \mathrm{ml}[38,70]$ \{strong consensus of the committee\}. Persistent severe PPH requires a multidisciplinary approach and early involvement of the most experienced members of the team $[17,21]$.

If blood loss exceeds $1,500 \mathrm{ml}$, oxygen delivery must be secured and regional anaesthesia might possibly be switched to general anaesthesia \{strong consensus of the committee\}.

Following intubation, the anaesthesiologist should immediately insert two large bore cannulae $(\geq 16 \mathrm{G})$ or one central access $(\geq 9 \mathrm{Fr})$ $[71,72]$ strong consensus of the committee\}. In haemodynamically centralised patients, peripheral venous access is likely to be less effective; thus, one large bore central line might be preferable, as volume and catecholamines can better reach the heart [71-73].

Installation of an invasive, arterial line should be performed after the volume access when personal resources are sufficient \{strong consensus of the committee\}.

Multiple international societies recommend the use of cell salvage in PPH (e.g., American Society of Anesthesiologists (ASA), Centre for Maternal and Child Enquiries (CMACE), European Society of Anaesthesiology (ESA), National Institute for Health and Care Excellence (NICE), Obstetric Anaesthetists' Association / Association of Anaesthetists of Great Britain and Ireland (OAA/ AAGBI)). For unpredictable haemorrhage, the device should be initially in 'stand-by' mode using only the reservoir; if needed; additionally, 'washing \& re-infusing' (i.e., added bowl and tubes) is possible [74]. In obstetrics, the method of two suction devices should be used: a regular surgical suction device for amniotic fluid, then switching to the cell saver's suction [74]. Usage of intra-operative cell salvage in elective caesarean delivery might reduce allogenic blood transfusions and length of stay. The following caveats should be considered \{strong consensus of the committee\}:

Cell savers provide only RBCs; substitution of coagulation factors and platelets might be necessary in addition.
Leucocyte depletion filters (LDFs) may lead to hypotension [75]. Yet, these filters seem to play a pivotal role in removing components of amnion fluid [76]. Recent reviews recommend using LDFs [77].

Some additional information on LDFs that is not part of the guideline: LDF are mostly made of polyurethane with very small pores $(\sim 40 \mu \mathrm{m})$. Their effect is caused by a combination of passive filtering and active adhesion on negatively charged surface. Therefore, they have a slow flow rate (e.g., Pall's LeukoGuard ${ }^{\mathrm{TM}} \sim 50$ $\mathrm{ml} / \mathrm{min}$ ) and the use of pressure infusion systems (like LevelOne ${ }^{\mathrm{TM}}$ or Fluido ${ }^{\mathrm{TM}}$ ) is not possible. There are 3 published obstetrical cases with hypotonia related to $\operatorname{LDF}[75,78,79]$. Most LDFs do not extract $\alpha$-foeto-protein, tissue factor, endothelin-1 or meconium, but these are removed by different integrated filters in the reservoir and bowl [76]. Following filtration, the particulate levels in salvaged blood are comparable to maternal levels [80]. A 'contamination' is only possible by foetal RBCs, that might cause a theoretically possible allo-immunisation [74]. With D-negative mother and D-positive child, a Rhesus prophylaxis after Kleihauer-Betke testing is recommended [80].

The foetus' perfusion is dependent on the mother's blood pressure. But after cutting the umbilical cord, the haemodynamics of a previously healthy young parturient with $\mathrm{PPH}$ should, as long as she is bleeding, be managed with 'permissive hypotension' by restrictive fluid application aiming at a palpable radial pulse [81, 82]. Until surgical haemostasis is reached, RBC transfusion should aim at securing a haemoglobin level of $7 \mathrm{~g} / \mathrm{dl}(4,3 \mathrm{mmol} / \mathrm{l})$; when haemostasis is obtained, the target level should be 7-9 $\mathrm{g} / \mathrm{dl}$ (4,3-5,6 $\mathrm{mmol} / \mathrm{l})$ \{strong consensus of the committee\}. Transfusions should be halted as soon as bleeding is controlled, with a shift towards a restrictive and goal-directed use of blood components [83]. Additionally, post-operative iron replacement therapy is recommended to enhance erythropoiesis when haemoglobin levels are low.

Table 3 contains an escalating scheme of haemostatic therapeutic options for PPH.

Time is of great essence in PPH management. While the results of standard laboratory parameters take more than $45 \mathrm{~min}$ [84] and are of limited value to predict or monitor coagulopathy, particularly in women with ongoing peripartum bleeding [85], the socalled 'viscoelastic tests' ROTEM and TEG provide earlier results, sometimes within 5-10 min [86,87]. With increasing evidence, the ESA guidelines advocate use of viscoelastic tests - though with a weak grade of recommendation - to guide haemostatic therapy in PPH [21]. The Subcommittees on Women's Health Issues of the International Society on Thrombosis and Haemostasis (ISTH) suggest that blood product replacement based on viscoelastic tests supported by a local algorithm is likely to be at least as efficacious as replacement based on laboratory testing and advocate maintaining a fibrinogen level of FIBTEM A5 > $12 \mathrm{~mm}$ [49]. It must be recognised, however, that viscoelastic tests cannot provide quantification of single analytes.

Following PPH, an individually adapted active monitoring for at least $24 \mathrm{~h}$ is recommended \{strong consensus of the committee\}. This monitoring should be done by a team with sufficient knowledge of haemodynamics and resuscitation. 
Table 3. Escalating scheme of haemostatic therapeutic options for $\mathrm{PPH}\{\text { strong consensus of the committee }\}^{*}$

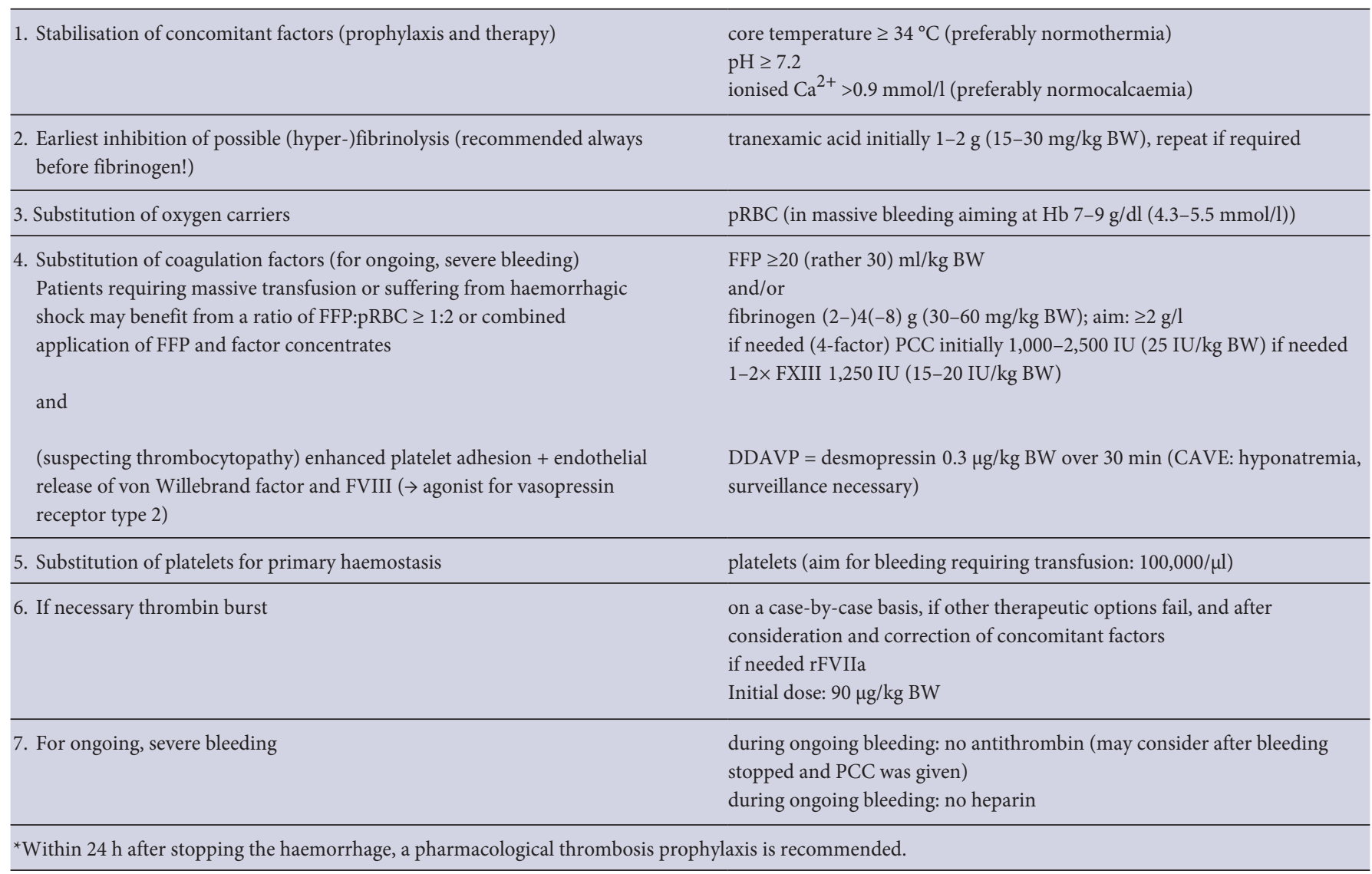

The difficult situation of PPH is an enormous source of stress for all participants and may cause post-traumatic stress disorders. An interdisciplinary team debriefing is recommended strong consensus of the committee\}. Regularly repeated simulations of bleeding situations should be done with all participants and will improve management \{strong consensus of the committee\}.

\section{Key Messages}

Essential for the effective and safe treatment of $\mathrm{PPH}$ is the timely diagnosis. The diagnosis of $\mathrm{PPH}$ requires the measurement rather than the estimation of blood loss.

Successful treatment of PPH requires a multidisciplinary approach involving surgical and medical (haemostatic) treatments to stop the bleeding.

Early monitoring of coagulation either by standard parameters or viscoelastic methods facilitates directed haemostatic treatment.

Haemostatic treatment of PPH starts early after diagnosis and combines TxA with coagulation factors (either concentrates or fresh frozen plasma).

\section{Addendum}

Following the acceptance of this manuscript, the results of the randomised, double-blind, placebo-controlled WOMAN-Trial were published by the Lancet.
A significant effect of TxA was proven for death due to bleeding (RR 0.81; 95\% CI $0.65-1.00 ; \mathrm{p}=0.045$ ), death if TxA was given within $3 \mathrm{~h}$ (RR 0.69; 95\% CI $0.52-0.91 ; \mathrm{p}=0.008$ ), and laparotomy to control bleeding (RR 0.64; 95\% CI $0.49-0.85 ; \mathrm{p}=0.002)$. There was a trend towards reduction of death from all cause but no difference in thromboembolic events. These results support the recommendations of the German guideline.

\section{Members of the German PPH Guideline Group}

Dr. med. Heiko Lier, Department of Anaesthesiology and Intensive Care Medicine, University Hospital Cologne, Cologne, Germany; Prof. Dr. med. Christian von Heymann, Department of Anaesthesiology, Intensive Care Medicine, Emergency Medicine and Pain Therapy, Vivantes Klinikum im Friedrichshain, Berlin, Germany; Prof. Dr. med. Wolfgang Korte, Centre for Laboratory Medicine and Haemostasis and Haemophilia Centre, St. Gallen, Switzerland; PD Dr. med. Dietmar Schlembach, Department of Obstetrics and Gynaecology, Vivantes Klinikum Neukölln, Berlin, Germany; Susanne Steppat, German Midwifes'Society, Karlsruhe, Germany; Prof. Dr. med. Maritta Kühnert, Department of Obstetrics and Gynaecology, Marburg, Germany; PD Dr. med. Holger Maul, Department of Obstetrics and Gynaecology, Katholisches Marienkrankenhaus gGmbH, Hamburg, Germany; Prof. Dr. med. Wolfgang Henrich, Charité Department of Obstetrics, Berlin, Germany; Prof. Dr. med. Werner Rath, Department of Obstetrics and Gynaecology, Aachen, Germany; Prof. Dr. med. Jürgen Wacker, Department of Gynaecology, Fürst-StirumKlinik Bruchsal, Bruchsal, Germany; Prof. Dr. med. Franz Kainer, Department of Obstetrics and Gynaecology, Klinik Hallerwiese, Nürnberg, Germany; Prof. Dr. med. Daniel Surbek, Department of Obstetrics and Gynaecology, Inselspital Bern, Bern, Switzerland; Prof. Dr. med. Hanns Helmer, Department of Obstetrics and Gynaecology, Vienna, Austria. 


\section{Disclosure Statement}

HL: Travel expenses and lecture fees from Bayer Vital, DRK blood donation service west, CSL Behring, Ferring, Mitsubishi Pharma, NovoNordisk, Tem International.

$\mathrm{CvH}$ : Related to the topic of this article, $\mathrm{CvH}$ has received, travel expenses and lecture fees from CSL Behring, Ferring, Novo Nordisk, Octapharma, Haemonetics and HICC GbR.
WK: Within the last 3 years, travel support, advisory fees, lecture fees and research support from CSL Behring, Novo Nordisk, Haemonetics, Octapharma, HICC, AxonLab, Roche Diagnostics, Bayer Vital, Boehringer Ingelheim, Pfizer, Bristol Myers Squibb, AstraZeneca, Daichii Sankyo, Vifor.

DS: Travel expenses and lecture fees from CSL Behring, Cook Medical, Clinical Innovations.

\section{References}

1 Weeks A: The prevention and treatment of postpartum haemorrhage: what do we know, and where do we go to next? BJOG 2015;122:202-210

2 Hofmeyr GJ, Qureshi Z: Preventing deaths due to haemorrhage. Best Pract Res Clin Obstet Gynaecol 2016;36:68-82.

3 Bonnar J: Massive obstetric haemorrhage. Baillieres Best Pract Res Clin Obstet Gynaecol 2000;14:1-18

4 Samangaya R, Pennington R, Vause S: Factors relating to a rising incidence of major postpartum haemorrhage. BJOG 2010;117:370-371.

5 Creanga AA, Berg CJ, Syverson C, Seed K, Bruce FC, Callaghan WM: Pregnancy-related mortality in the United States, 2006-2010. Obstet Gynecol 2015;125: 5-12.

6 Callaghan WM, Kuklina EV, Berg CJ: Trends in postpartum hemorrhage: United States, 1994-2006. Am J Obstet Gynecol 2010;202:353-356.

7 Muir HA: Pharmacologic intervention for managing uterine atony and related maternal hemorrhage: what is the most effective drug dose? Can J Anaesth 2013;60 1047-1053.

8 Dutton RP, Lee LA, Stephens LS, Posner KL, Davies JM, Domino KB: Massive hemorrhage. A report from the Anesthesia Closed Claims Project. Anesthesiology 2014;121:450-458.

9 Bohlmann MK, Rath W: Medical prevention and treatment of postpartum hemorrhage: a comparison of different guidelines. Arch Gynecol Obstet 2014;289:555567.

10 Schlembach D, Mortl MG, Girard T, Arzt W, Beinder E, Brezinka C, Chalubinski K, Fries D, Gogarten W, Hackeloer BJ, Helmer H, Henrich W, Hosli I, Husslein P, Kainer F, Lang U, Pfanner G, Rath W, Schleussner E, Steiner H, Surbek D, Zimmermann R: Management of postpartum hemorrhage (PPH): algorithm of the interdisciplinary D-A-CH consensus group PPH (Germany - Austria - Switzerland) (in German). Anaesthesist 2014;63:234-242.

11 DeLee J: A case of fatal hemorrhagic diathesis, with premature detachment of the placenta. Am J Obstet Gynecol 1901;44:785-792.

12 Shaylor R, Weiniger CF, Austin N, Tzabazis A, Shander A, Goodnough LT, Butwick AJ: National and international guidelines for patient blood management in obstetrics: a qualitative review. Anesth Analg 2017; 124:216-232.

13 Arbeitsgemeinschaft der Wissenschaftlichen Medizinischen Fachgesellschaften e.V. (AWMF, Association of scientific medical societies in Germany): AWMF Guidance Manual and Rules for Guideline Development. 2012. www.awmf.org/fileadmin/user_upload/ Leitlinien/AWMF-Regelwerk/AWMF-Guidance_2013. pdf (last accessed August 30, 2017).

14 Tuncalp O, Souza JP, Gulmezoglu M, World Health O: New WHO recommendations on prevention and treatment of postpartum hemorrhage. Int J Gynaecol Obstet 2013;123:254-256.
15 American College of Obstetricians Gynecologists (ACOG): ACOG Practice Bulletin: Clinical Management Guidelines for Obstetrician-Gynecologists Number 76, October 2006:postpartum hemorrhage. Obstet Gynecol 2006;108:1039-1047.

16 Neb H, Zacharowski K, Meybohm P: Strategies to reduce blood product utilization in obstetric practice. Curr Opin Anaesthesiol 2017;30:294-299.

17 Abdul-Kadir R, McLintock C, Ducloy AS, El-Refaey H, England A, Federici AB, Grotegut CA, Halimeh S, Herman JH, Hofer S, James AH, Kouides PA, Paidas MJ, Peyvandi F, Winikoff R: Evaluation and management of postpartum hemorrhage: consensus from an international expert panel. Transfusion 2014;54:1756-1768

18 Kramer MS, Berg C, Abenhaim H, Dahhou M, Rouleau J, Mehrabadi A, Joseph KS: Incidence, risk factors, and temporal trends in severe postpartum hemorrhage. Am J Obstet Gynecol 2013;209:449 e441-447.

19 Antony KM, Dildy GA, 3rd: Postpartum hemorrhage: the role of the Maternal-fetal medicine specialist in enhancing quality and patient safety. Semin Perinatol 2013;37:246-256.

20 Main EK, Goffman D, Scavone BM, Low LK, Bingham D, Fontaine PL, Gorlin JB, Lagrew DC, Levy BS; National Parntership for Maternal Safety, Council for Patient Safety in Women's Health Care: National Partnership for Maternal Safety: consensus bundle on obstetric hemorrhage. Anesth Analg 2015;121:142-148.

21 Kozek-Langenecker SA, Afshari A, Albaladejo P, Santullano CA, De RE, Filipescu DC, Fries D, Gorlinger K, Haas T, Imberger G, Jacob M, Lance M, Llau J, Mallett S, Meier J, Rahe-Meyer N, Samama CM, Smith A, Solomon C, Van der Linden P, Wikkelso AJ, Wouters P, Wyffels P: Management of severe perioperative bleeding: Guidelines from the European Society of Anaesthesiology. Eur J Anaesthesiol 2013;30:270-382.

22 Rajan PV, Wing DA: Postpartum hemorrhage: evidence-based medical interventions for prevention and treatment. Clin Obstet Gynecol 2010;53:165-181.

23 Siboni SM, Spreafico M, Calo L, Maino A, Santagostino E, Federici AB, Peyvandi F: Gynaecological and obstetrical problems in women with different bleeding disorders. Haemophilia 2009;15:1291-1299.

24 Lee CA, Chi C, Pavord SR, Bolton-Maggs PH, Pollard D, Hinchcliffe-Wood A, Kadir RA: The obstetric and gynaecological management of women with inherited bleeding disorders - review with guidelines produced by a taskforce of UK Haemophilia Centre Doctors' Organization. Haemophilia 2006;12:301-336.

25 Baskett TF: A flux of the reds: evolution of active management of the third stage of labour. J R Soc Med 2000; 93:489-493.

26 Carvalho JC, Balki M, Kingdom J, Windrim R: Oxytocin requirements at elective cesarean delivery: a dosefinding study. Obstet Gynecol 2004;104:1005-1010.

27 George RB, McKeen D, Chaplin AC, McLeod L: Updown determination of the $\mathrm{ED}(90)$ of oxytocin infusions for the prevention of postpartum uterine atony in parturients undergoing Cesarean delivery. Can J Anaesth 2010;57:578-582.
28 Rossi AC, Lee RH, Chmait RH: Emergency postpartum hysterectomy for uncontrolled postpartum bleeding: a systematic review. Obstet Gynecol 2010;115: 637-644.

29 Balki M, Tsen L: Oxytocin protocols for cesarean delivery. Int Anesthesiol Clin 2014;52:48-66.

30 Lavoie A, McCarthy RJ, Wong CA: The ED90 of prophylactic oxytocin infusion after delivery of the placenta during cesarean delivery in laboring compared with nonlaboring women: an up-down sequential allocation dose-response study. Anesth Analg 2015;121: 159-164.

31 Dyer RA, Butwick AJ, Carvalho B: Oxytocin for labour and caesarean delivery: implications for the anaesthesiologist. Curr Opin Anaesthesiol 2011;24:255-261.

32 Kenyon S, Tokumasu H, Dowswell T, Pledge D, Mori R: High-dose versus low-dose oxytocin for augmentation of delayed labour. Cochrane Database Syst Rev 2013;7:CD007201.

33 Stephens LC, Bruessel T: Systematic review of oxytocin dosing at caesarean section. Anaesth Intensive Care 2012;40:247-252.

34 Zwolińska E, Zwoliński J: The use of carbetocin in prevention and treatment of $\mathrm{PPH}$. 13th World Congress in Fetal Medicine. https://fetalmedicine.org/abstracts/ 2014/abstracts/149.pdf (last accessed August 30, 2017).

35 Gizzo S, Patrelli TS, Gangi SD, Carrozzini M, Saccardi C, Zambon A, Bertocco A, Fagherazzi S, D'Antona D, Nardelli GB: Which uterotonic is better to prevent the postpartum hemorrhage? Latest news in terms of clinical efficacy, side effects, and contraindications: a systematic review. Reprod Sci 2013;20:1011-1019.

36 Lampati L, Colantonio LB, Calderini E: Cardiac arrest during sulprostone administration - a case report. Acta Anaesthesiol Scand 2013;57:395-397.

37 Henrich W, Surbek D, Kainer F, Grottke O, Hopp H, Kiesewetter H, Koscielny J, Maul H, Schlembach D, von Tempelhoff GF, Rath W: Diagnosis and treatment of peripartum bleeding. J Perinat Med 2008;36:467-478.

38 Ahonen J, Stefanovic V, Lassila R: Management of post-partum haemorrhage. Acta Anaesthesiol Scand 2010;54:1164-1178.

39 Green L, Knight M, Seeney FM, Hopkinson C, Collins PW, Collis RE, Simpson N, Weeks A, Stanworth SS: The epidemiology and outcomes of women with postpartum haemorrhage requiring massive transfusion with eight or more units of red cells: a national crosssectional study. BJOG 2016;123:2164-2170.

40 Weeks AD, Mallaiah S: Beyond MBRRACE: new developments to stem the tide of postpartum haemorrhage. Eur J Obstet Gynecol Reprod Biol 2016;199:66-68.

41 Ahonen J: The role of recombinant activated factor VII in obstetric hemorrhage. Curr Opin Anaesthesiol 2012; 25:309-314.

42 de Lange NM, Lance MD, de GR, Beckers EA, Henskens YM, Scheepers HC: Obstetric hemorrhage and coagulation: an update. Thromboelastography, thromboelastometry, and conventional coagulation tests in the diagnosis and prediction of postpartum hemorrhage. Obstet Gynecol Surv 2012;67:426-435. 
43 James AH, McLintock C, Lockhart E: Postpartum hemorrhage: when uterotonics and sutures fail. Am J Hematol 2012;87(suppl 1):S16-S22.

44 Thachil J, Toh CH: Disseminated intravascular coagulation in obstetric disorders and its acute haematological management. Blood Rev 2009;23:167-176.

45 Hofmann-Kiefer KF, Knabl J, Martinoff N, Schiessl B, Conzen P, Rehm M, Becker BF, Chappell D: Increased serum concentrations of circulating glycocalyx components in HELLP syndrome compared to healthy pregnancy: an observational study. Reprod Sci 2013;20: 318-325.

46 Djelmis J, Ivanisevic M, Kurjak A, Mayer D: Hemostatic problems before, during and after delivery. J Perinat Med 2001;29:241-246.

47 Solomon C, Collis RE, Collins PW: Haemostatic monitoring during postpartum haemorrhage and implications for management. Br J Anaesth 2012;109:851-863.

48 McLintock C, James AH: Obstetric hemorrhage. J Thromb Haemost 2011;9:1441-1451.

49 Collins P, Abdul-Kadir R, Thachil J; for the Subcommittees on Women's Health Issues in Thrombosis and Haemostasis and on Disseminated Intravascular Coagulation: Management of coagulopathy associated with postpartum hemorrhage: guidance from the SSC of the ISTH. J Thromb Haemost 2016;14:205-210

50 Ducloy-Bouthors AS, Jude B, Duhamel A, Broisin F, Huissoud C, Keita-Meyer H, Mandelbrot L, Tillouche N, Fontaine S, Le GF, Depret-Mosser S, Vallet B, Group ES, Susen S: High-dose tranexamic acid reduces blood loss in post-partum haemorrhage. Crit Care 2011;15:R117

51 Ducloy-Bouthors AS, Duhamel A, Kipnis E, Tournoys A, Prado-Dupont A, Elkalioubie A, Jeanpierre E, Debize G, Peynaud-Debayle E, DeProst D, Huissoud C, Rauch A, Susen S: Postpartum haemorrhage related early increase in D-dimers is inhibited by tranexamic acid: haemostasis parameters of a randomized controlled open labelled trial. Br J Anaesth 2016;116:641-648.

52 Shakur H, Elbourne D, Gulmezoglu M, Alfirevic Z, Ronsmans C, Allen E, Roberts I: The WOMAN Trial (World Maternal Antifibrinolytic Trial): tranexamic acid for the treatment of postpartum haemorrhage: an international randomised, double blind placebo controlled trial. Trials 2010;11:40.

53 Moloney W, Phillips L, Pritchard J, Ratnoff O, Reid D, Schneider C: Management of the obstetrical patient with hemorrhage due to an acute or subacute defibrination syndrome. Blood 1959;14:1354-1367.

54 Collis RE, Collins PW: Haemostatic management of obstetric haemorrhage. Anaesthesia 2015;70(suppl 1): 78-86, e27-78.

55 Niepraschk-von Dollen K, Bamberg C, Henkelmann A, Mickley L, Kaufner L, Henrich W, Pauly F: Predelivery maternal fibrinogen as a predictor of blood loss after vaginal delivery. Arch Gynecol Obstet 2016;294: 745-751.

56 Mallaiah S, Barclay P, Harrod I, Chevannes C, Bhalla A: Introduction of an algorithm for ROTEM-guided fibrinogen concentrate administration in major obstetric haemorrhage. Anaesthesia 2015;70:166-175.

57 Wikkelso AJ, Edwards HM, Afshari A, Stensballe J, Langhoff-Roos J, Albrechtsen C, Ekelund K, Hanke G, Secher EL, Sharif HF, Pedersen LM, Troelstrup A, Lauenborg J, Mitchell AU, Fuhrmann L, Svare J, Madsen MG, Bodker B, Moller AM, group F-Pt: Pre-emptive treatment with fibrinogen concentrate for postpartum haemorrhage: randomized controlled trial. $\mathrm{Br}$ Anaesth 2015;114:623-633.

58 Trigg DE, Stergiotou I, Peitsidis P, Kadir RA: A systematic review: the use of desmopressin for treatment and prophylaxis of bleeding disorders in pregnancy. Haemophilia 2012;18:25-33.
59 Alfirevic Z, Elbourne D, Pavord S, Bolte A, Van Geijn H, Mercier F, Ahonen J, Bremme K, Bodker B, Magnusdottir EM, Salvesen K, Prendiville W, Truesdale A, Clemens F, Piercy D, Gyte G: Use of recombinant activated factor VII in primary postpartum hemorrhage: the Northern European registry 2000-2004. Obstet Gynecol 2007;110:1270-1278.

60 Phillips LE, McLintock C, Pollock W, Gatt S, Popham P, Jankelowitz G, Ogle R, Cameron PA; Australian and New Zealand Haemostasis Registry: Recombinant activated factor VII in obstetric hemorrhage: experiences from the Australian and New Zealand Haemostasis Registry. Anesth Analg 2009;109:1908-1915.

61 Zatta A, McQuilten Z, Kandane-Rathnayake R, Isbister J, Dunkley S, McNeil J, Cameron P, Phillips L: The Australian and New Zealand Haemostasis Registry: ten years of data on off-licence use of recombinant activated factor VII. Blood Transfus 2015;13:86-99.

62 Lavigne-Lissalde G, Aya AG, Mercier FJ, Roger-Christoph S, Chauleur C, Morau E, Ducloy-Bouthors AS, Mignon A, Raucoules M, Bongain A, Boehlen F, de Moerloose P, Bouvet S, Fabbro-Peray P, Gris JC: Recombinant human FVIIa for reducing the need for invasive second-line therapies in severe refractory postpartum hemorrhage: a multicenter, randomized, open controlled trial. J Thromb Haemost 2015;13:520-529.

63 Peitsidis P, Kadir RA: Antifibrinolytic therapy with tranexamic acid in pregnancy and postpartum. Expert Opin Pharmacother 2011;12:503-516.

64 Lier H, Krep H, Schroeder S, Stuber F: Preconditions of hemostasis in trauma: a review. The influence of acidosis, hypocalcemia, anemia, and hypothermia on functional hemostasis in trauma. J Trauma 2008;65: 951-960.

65 Royal College of Obstetricians and Gynaecologists (RCOG): Reducing the Risk of Venous Thromboembolism during Pregnancy and the Puerperium. Greentop Guideline No. 37a. www.rcog.org.uk/globalassets/ documents/guidelines/gtg-37a.pdf (last accessed August 30, 2017).

66 Schochl H, Voelckel W, Maegele M, Kirchmair L, Schlimp CJ: Endogenous thrombin potential following hemostatic therapy with 4 -factor prothrombin complex concentrate: a 7-day observational study of trauma patients. Crit Care 2014:R147.

67 Karlsson O, Jeppsson A, Hellgren M: Major obstetric haemorrhage: monitoring with thromboelastography, laboratory analyses or both? Int J Obstet Anesth 2014; 23:10-17.

68 James AH, Konkle BA, Bauer KA: Prevention and treatment of venous thromboembolism in pregnancy in patients with hereditary antithrombin deficiency. Int J Women Health 2013;5:233-241.

69 Karlsson O, Sporrong T, Hillarp A, Jeppsson A, Hellgren $\mathrm{M}$ : Prospective longitudinal study of thromboelastography and standard hemostatic laboratory tests in healthy women during normal pregnancy. Anesth Analg 2012;115:890-898

70 Rossen J, Okland I, Nilsen OB, Eggebo TM: Is there an increase of postpartum hemorrhage, and is severe hemorrhage associated with more frequent use of obstetric interventions? Acta Obstet Gynecol Scand 2010; 89:1248-1255.

71 Fuller AJ, Bucklin BA: Blood product replacement for postpartum hemorrhage. Clin Obstet Gynecol 2010;53: 196-208.

72 National Institute for Health and Clinical Excellence (NICE): Major trauma: Assessment and Initial Management (NG39),.2016. www.nice.org.uk/guidance/ ng39 (last accessed August 30, 2017).
73 Bonnet MP, Deneux-Tharaux C, Bouvier-Colle MH: Critical care and transfusion management in maternal deaths from postpartum haemorrhage. Eur J Obstet Gynecol Reprod Biol 2011;158:183-188.

74 Liumbruno GM, Meschini A, Liumbruno C, Rafanelli $\mathrm{D}$ : The introduction of intra-operative cell salvage in obstetric clinical practice: a review of the available evidence. Eur J Obstet Gynecol Reprod Biol 2011;159: $19-25$.

75 Waldron S: Hypotension associated with leucocyte depletion filters following cell salvage in obstetrics. Anaesthesia 2011;66:133-134.

76 Campbell JP, Mackenzie MJ, Yentis SM, Sooranna SR, Johnson MR: An evaluation of the ability of leucocyte depletion filters to remove components of amniotic fluid. Anaesthesia 2012;67:1152-1157.

77 Goucher H, Wong CA, Patel SK, Toledo P: Cell Salvage in Obstetrics. Anesth Analg 2015;121:465-468.

78 Sreelakshmi TR, Eldridge J: Acute hypotension associated with leucocyte depletion filters during cell salvaged blood transfusion. Anaesthesia 2010;65:742744

79 Kessack LK, Hawkins N: Severe hypotension related to cell salvaged blood transfusion in obstetrics. Anaesthesia 2010;65:745-748.

80 James AH, Grotegut C, Ahmadzia H, Peterson-Layne C, Lockhart E: Management of coagulopathy in postpartum hemorrhage. Semin Thromb Hemost 2016;42: 724-731.

81 Pacheco LD, Saade GR, Gei AF, Hankins GD: Cuttingedge advances in the medical management of obstetrical hemorrhage. Am J Obstet Gynecol 2011;205:526532

82 Cotton BA, Au BK, Nunez TC, Gunter OL, Robertson AM, Young PP: Predefined massive transfusion protocols are associated with a reduction in organ failure and postinjury complications. J Trauma 2009;66:41-

83 Ekelund K, Hanke G, Stensballe J, Wikkelsoe A, Albrechtsen CK, Afshari A: Hemostatic resuscitation in postpartum hemorrhage - a supplement to surgery. Acta Obstet Gynecol Scand 2015;94:680-692.

84 Toulon P, Ozier Y, Ankri A, Fleron MH, Leroux G, Samama CM: Point-of-care versus central laboratory coagulation testing during haemorrhagic surgery. A multicenter study. Thromb Haemost 2009;101:394-401.

85 Panteleev MA, Hemker HC: Global/integral assays in hemostasis diagnostics: promises, successes, problems and prospects. Thromb J 2015;13:5.

86 de Lange NM, van Rheenen-Flach LE, Lance MD, Mooyman L, Woiski M, van Pampus EC, Porath M, Bolte AC, Smits L, Henskens YM, Scheepers HC: Peripartum reference ranges for ROTEM $(\mathrm{R})$ thromboelastometry. Br J Anaesth 2014;112:852-859.

87 Collins PW, Lilley G, Bruynseels D, Laurent DB, Cannings-John R, Precious E, Hamlyn V, Sanders J, Alikhan R, Rayment R, Rees A, Kaye A, Hall JE, Paranjothy S, Weeks A, Collis RE: Fibrin-based clot formation as an early and rapid biomarker for progression of postpartum hemorrhage: a prospective study. Blood 2014;124:1727-1736.

88 Lier H, Hinkelbein J: Coagulation therapy in multiple trauma without point-of-care testing (in German). Unfallchirurg 2014;117:105-110.

89 Lier H, Rath W: Aktuelle interdisziplinäre Handlungsempfehlungen bei schweren peri-(post-) partalen Blutungen (PPH). Geburtsh Frauenheilk 2011;17:577588. 